\title{
Infection Studies of Mycosphaerella fijiensis on Banana and the Control of Black Sigatoka with Chlorothalonil
}

\author{
J. R. Washington, J. Cruz, F. Lopez, and M. Fajardo, ISK Biosciences Corporation, La Lima, Honduras
}

\begin{abstract}
Washington, J. R., Cruz, J., Lopez, F., and Fajardo, M. 1998. Infection studies of Mycosphaerella fijiensis on banana and the control of black Sigatoka with chlorothalonil. Plant Dis. 82:1185-1190.

Infection studies with Mycosphaerella fijiensis, causal agent of black Sigatoka disease of banana (Musa AAA), demonstrated that the abaxial leaf surface is the primary infection site. Inoculation of banana plants with $M$. fijiensis ascospores on the abaxial surface of young leaves resulted in disease symptoms in $100 \%$ of the leaves inoculated within 18 to 30 days; whereas only $5 \%$ of the leaves inoculated on the adaxial surface showed black Sigatoka symptoms within 10 weeks. Disease symptoms appeared more rapidly on the new, emerging leaves than on the first and second fully expanded leaves. Application of chlorothalonil $\left(1.08 \mathrm{~kg}\right.$ a.i. $\left.\mathrm{ha}^{-1}\right)$ to the abaxial surface of emerging leaves resulted in 99 to $100 \%$ disease control in the treated area. When the emerging leaf was not sprayed until fully expanded, disease control was reduced to 76 to $80 \%$. Application of chlorothalonil to the adaxial surface of banana leaves had little or no impact on disease control. Chlorothalonil arrested hyphal growth when applied to banana leaves after ascospores had already germinated and reduced the rate of lesion expansion when applied to the abaxial leaf surface after symptom appearance. Chlorothalonil was less effective than systemic fungicides in reducing production of $M$. fijiensis pseudothecia in infected tissue. When systemic and protectant fungicides were applied to infected leaf tissue, none of the fungicides affected the viability of ascospores that were discharged from pseudothecia produced in that tissue. For successful control of black Sigatoka with chlorothalonil, deposition of the fungicide on the abaxial leaf surface is essential.
\end{abstract}

Black Sigatoka, which is caused by $M y$ cosphaerella fijiensis Morelet, is the major limiting factor in banana (Musa AAA) production where it occurs worldwide (14). Banana plantations producing fruit for the international export market must use intensive fungicide spray programs in order to maintain satisfactory disease control. In many areas of Central America, fungicide sprays are applied weekly; spray programs generally consist of both systemic and protectant fungicides, applied in alternation, tank mixes, or at different times of the year depending on local preferences. The protectant fungicides chlorothalonil and mancozeb are important components of black Sigatoka fungicide programs, representing 50 to $90 \%$ of the total number of fungicide applications. The use of protectant fungicides for the control of this disease has increased in recent years due to a common perception among growers of a reduced efficacy of systemic fungicides in

Corresponding author: J. R. Washington, 6964 NW 55th St., Suite DFFI, Miami, FL 33166-5632.

Accepted for publication 3 August 1998.

Publication no. D-1998-0901-01R

(C) 1998 The American Phytopathological Society the field and indications of reduced sensitivity of $M$. fijiensis to triazole fungicides such as propiconazole (9). However, the specific mechanisms describing how protectant fungicides control black Sigatoka under field conditions is poorly documented. Accordingly, recommendations for application frequency and use patterns of protectant fungicides in banana are highly variable and controversial. In commercial banana plantations, fungicides are applied by aircraft at low spray volumes (15 to 25 liters $\mathrm{ha}^{-1}$ ). Most of the fungicide is deposited on the adaxial leaf surface. Stover (14) stated that infection by $M$. fijiensis occurs primarily on the abaxial leaf surface, but no data were presented. Stover (17) concluded that "protectants play only a minor role in control of $M$. fijiensis during periods of abundant ascospore production and weather favorable for infection." However, Stover (15) also reported that "chlorothalonil retards or stops development of young lesions and proved highly effective for the control of black Sigatoka." For the closely related pathogen Mycosphaerella musicola, causal agent of yellow Sigatoka of banana, Bordeaux mixture applied on the adaxial surface of banana leaves had little effect on disease control; whereas application on the abaxial leaf surface resulted in $86 \%$ reduction in leaf spotting (6). Similarly, Stahel
(12) and Simmonds (11) reported that for control of yellow Sigatoka, the protectant action of Bordeaux mixture was more effective when applied to the abaxial rather than the adaxial surface of the youngest leaves. Klein (5) reported that when Bordeaux mixture was applied to both the adaxial and abaxial surface on banana leaves, $100 \%$ control of yellow Sigatoka was obtained. None of these reports included definitive infection studies comparing adaxial and abaxial leaf surface inoculation with ascospores, and no studies have been published evaluating the impact of adaxial or abaxial leaf surface application of chlorothalonil, a commonly used fungicide in the banana industry. Additionally, field assessment of spray application coverage of protectant fungicides in banana are currently assessed by quantifying droplet deposits per $\mathrm{cm}^{2}$ recovered on the adaxial surface of banana leaves or on water-sensitive paper placed horizontally in the field below the airplane spray swath (20). If disease control is indeed obtained by fungicide on the abaxial leaf surface, then the current methods of spraying and coverage assessment may be inappropriate.

The objectives of this study were to determine the relative importance of the adaxial and abaxial leaf surfaces for infection by $M$. fijiensis and to assess the effect of chlorothalonil on development of primary infection on both leaf surfaces.

\section{MATERIALS AND METHODS}

Infection studies. Banana plants (Musa AAA Grand Nain) were inoculated with $M$. fijiensis ascospores by suspending infected leaf tissue containing pseudothecia over the adaxial or abaxial surface of leaves. The banana plants were contained in $40 \times$ $40 \mathrm{~cm}$ black polyethylene bags. The potting soil used was a sandy clay loam obtained from a local banana plantation (Banderas Farm). Ascospores were chosen as the inoculum source since they are considered the most important source of inoculum in the field $(15,21)$. Plants were maintained outdoors in full sunlight at ISK Biosciences' research facility in La Lima, Honduras, an area isolated from commercial banana plantations by at least $2 \mathrm{~km}$ in all directions. The experiments were conducted from August to October 1997 during the rainy season when disease development is the most rapid (8). For 
inoculation of leaves 1 and 2, representing the first and second youngest fully expanded leaves, respectively, infected, necrotic leaf tissue with mature pseudothecia was cut into $2 \times 2 \mathrm{~cm}$ pieces, stapled onto filter paper, and placed in the bottom of glass, 9-cm-diameter petri dishes. The filter paper with attached pseudothecia was soaked in sterile distilled water for $10 \mathrm{~min}$ to induce ascospore release and then inverted over the banana leaves for $30 \mathrm{~min}$. Infested leaf tissue was changed three times to ensure the discharge of sufficient inoculum for each leaf. Due to the absence of a suitable technique for isolating $M$. fijiensis ascospores in a liquid suspension, a precise quantity of inoculum per leaf area could not be achieved. However, parallel inoculations of leaves revealed that inoculated leaves received 5 to 30 ascospores per $\mathrm{cm}^{2}$ within the 9 -cm-diameter, circular inoculated area. For inoculation of the emerging leaf, which is rolled up in a cylinder during its emergence, necrotic leaf tissue with pseudothecia was stapled to the inside of two manila folders rolled up and attached end to end, creating an 8-cm-diameter cylinder that fit over the emerging leaf and exposed the abaxial leaf surface to discharged ascospores. Following inoculation with ascospores, leaves were examined daily for infection symptoms on both leaf surfaces. The final assessment of the percentage of leaves infested was conducted 10 weeks following inoculation. The experiment was conducted twice using a completely random design with 20 replicates (plants) per treatment.

Fungicide studies. The effect of chlorothalonil (BRAVO 720, $720 \mathrm{~g}$ a.i. liter $^{-1}$, ISK Biosciences, Houston, TX) applied on the adaxial and abaxial leaf surfaces was assessed in a 1-ha field plot established with banana plants (Musa AAA Grand Nain) located in Santa Rita, Yoro, Honduras. The experimental design was a randomized complete block with 12 treatments and six replications. The first experiment was conducted from September to December 1996, and the second experiment was run from August to November
1997. The treatments were designed to cover all possible combinations of emerging leaf protection (physical or chemical) from infection prior to a single chlorothalonil application to a $23 \times 23 \mathrm{~cm}$ marked area on either of the leaf surfaces. The 12 treatments (Table 1) were divided into three subgroups according to the mode of protecting the emerging leaf. The emerging leaves in treatments 1 through 4 were covered with a polyethylene bag placed loosely around the leaf. The bag was tied at the bottom and suspended from a bamboo tripod with its apex oriented directly above the plant. Emerging leaves in treatments 5 through 8 were left uncovered and unsprayed. The emerging leaves in treatments 8 through 12 were sprayed with a $1.5 \%$ (vol/vol) aqueous suspension of chlorothalonil on the abaxial surface when they were 4 days old, utilizing a Chromister (Fisher Scientific, Atlanta, GA) $\mathrm{CO}_{2}$-pressurized applicator connected by a rubber tube to a glass flask containing the fungicide suspension. The exposed portion of the abaxial surface of the emerging leaf was sprayed liberally but without runoff. Care was taken to avoid deposit on the adaxial leaf surface, and no effort was made to cover the unexposed leaf surface. When 4 days old, the emerging leaves were still rolled up and had about half of their abaxial leaf surface exposed to the spray. This area corresponded roughly to the abaxial leaf surface to the right of the midvein. When the emerging leaves were completely open and thus considered leaf 1 (youngest, fully emerged leaf), a $23 \times 23$ $\mathrm{cm}$ area was marked on the adaxial or abaxial leaf surfaces in an area to the left of the midvein (when viewed from the top) $10 \mathrm{~cm}$ from the leaf apex. This area was sprayed with chlorothalonil $(1.08 \mathrm{~kg}$ a.i. $\mathrm{ha}^{-1}$ ) utilizing a $23 \times 23 \times 80 \mathrm{~cm}$ spray tower as described by Calpouzos et al. (2). Leaves were sprayed on the adaxial surface, the abaxial surface, both surfaces, or left unsprayed according to the description in the third column of Table 1 . Final disease assessment was taken 8 weeks following the fungicide application. At the

Table 1. Percent control of black Sigatoka obtained on treated banana leaves

\begin{tabular}{lllll}
\hline \multirow{2}{*}{ Treatment } & $\begin{array}{c}\text { Protection of } \\
\text { emerging leaf }\end{array}$ & \multicolumn{1}{c}{$\begin{array}{c}\text { Fungicide application } \\
\text { on leaf 1 }\end{array}$} & \multicolumn{2}{c}{ Disease control (\%) } \\
\cline { 5 - 5 } & Polyethylene bag & Abaxial surface & $97.5 \mathrm{a}^{\mathrm{z}}$ & $89.5 \mathrm{ab}$ \\
2 & Polyethylene bag & Adaxial surface & $44.2 \mathrm{~d}$ & $61.3 \mathrm{c}$ \\
3 & Polyethylene bag & Adaxial + abaxial surface & $99.4 \mathrm{a}$ & $99.6 \mathrm{a}$ \\
4 & Polyethylene bag & None & $0.8 \mathrm{e}$ & $0.0 \mathrm{e}$ \\
5 & None & Abaxial surface & $75.7 \mathrm{c}$ & $80.8 \mathrm{~b}$ \\
6 & None & Adaxial surface & $0.0 \mathrm{e}$ & $13.2 \mathrm{~d}$ \\
7 & None & Adaxial + abaxial surface & $93.0 \mathrm{ab}$ & $92.9 \mathrm{a}$ \\
8 & None & None & $0.0 \mathrm{e}$ & $0.0 \mathrm{e}$ \\
9 & Chlorothalonil & Abaxial surface & $99.4 \mathrm{a}$ & $100 \mathrm{a}$ \\
10 & Chlorothalonil & Adaxial surface & $85.9 \mathrm{bc}$ & $87.0 \mathrm{~b}$ \\
11 & Chlorothalonil & Adaxial + abaxial surface & $100 \mathrm{a}$ & $100 \mathrm{a}$ \\
12 & Chlorothalonil & None & $83.7 \mathrm{bc}$ & $81.3 \mathrm{~b}$ \\
\hline
\end{tabular}

${ }^{\mathrm{z}}$ Data followed by the same letter in each column are not significantly different $(P>0.05)$ according to Tukey's test. Analysis was conducted on arcsine-transformed percentage data. time of final disease assessment, the untreated controls exhibited 75 to $100 \%$ necrotic tissue. Disease control in all treatments was expressed relative to the mean disease severity in the untreated control. An analysis of variance was performed on arcsine-transformed percent disease control (13) using SAS ver. 6.04 statistical software (SAS Institute, Cary, NC).

M. fijiensis pseudothecia production in banana leaves treated with fungicides was assessed by using the methods described by Stover and Dickson (18). The treatments were tridemorph (CALIXIN 250EC, $150 \mathrm{~g}$ a.i. $\mathrm{ha}^{-1}$, BASF Corp., Limburgerhof, Germany), propiconazole (TILT 250EC, $100 \mathrm{~g}$ a.i. ha $^{-1}$, Novartis Corp., Basle, Switzerland), azoxystrobin (BANKIT 250SC, $100 \mathrm{~g}$ a.i. ha ${ }^{-1}$, Zeneca Corp., Wilmington, DE), and chlorothalonil (BRAVO 720, $1.08 \mathrm{~kg}$ a.i. ha ${ }^{-1}$, ISK Biosciences, Houston, TX). Tridemorph, propiconazole, and azoxystrobin were applied in an oil-water emulsion using 5 liters of spray oil (ORCHEX 796, Exxon Corp., Houston, TX) per ha. Chlorothalonil was applied in water alone. All fungicides were applied with the $23 \times 23 \times 80 \mathrm{~cm}$ spray tower using a total spray volume of 20 liters $\mathrm{ha}^{-1}$. Three applications of each fungicide were made at 10-day intervals to the adaxial leaf surfaces beginning when infection streaks were first visible. Leaves were harvested 8 weeks after the first application. Subsamples of the leaf tissue were incubated in a moist chamber for $48 \mathrm{~h}$ and cleared in lactophenol, and pseudothecia were counted under the microscope at $\times 20$.

The effect of fungicides on the germination of ascospores produced from the fungicide-treated leaf tissue was assessed by taking four subsamples per leaf and discharging ascospores onto $2 \%$ water agar dishes using the method described previously. The experimental design in the field was a randomized complete block with six replications. Four subsamples were taken per leaf sample. One hundred ascospores were observed per subsample. The subsamples were averaged and counted as one data point. Data were analyzed by an analysis of variance (SAS, ver. 6.04).

Germ tube elongation bioassay. Ascospores were discharged onto twenty $9-\mathrm{cm}$ diameter banana leaf disks as described by Washington (20). The leaf disks were misted with sterile distilled water, placed on top of a moist paper towel in 9-cm glass petri dishes, and incubated on the lab bench for $48 \mathrm{~h}$. The mean germ tube length at $48 \mathrm{~h}$ was estimated by sampling four leaf disks cut into four even strips (subsamples) and staining them for $10 \mathrm{~min}$ in a $1 \%$ Rose Bengal (Fisher Scientific) solution. Leaf samples were rinsed of excess stain and examined at $\times 100$ magnification under a compound microscope. Germ tube length was measured for 100 
ascospores per subsample (400 spores per leaf disk). The chlorothalonil treatment was applied $48 \mathrm{~h}$ after inoculation to eight leaf disks using a Chromist applicator. Eight leaf disks were left untreated and served as controls. Twenty-four and $48 \mathrm{~h}$ later (corresponding to 72 and $96 \mathrm{~h}$ after inoculation), four leaf disks per treatment were stained and germ tubes were measured. In this way, mean germ tube length was quantified in the chlorothalonilsprayed and untreated leaf disks at two time intervals following the chlorothalonil application. The experiment was conducted three times. The error variances were homogenous according to Bartlett's test, so data were combined among experiments prior to analysis.

Effect of chlorothalonil on lesion expansion. The effect of chlorothalonil on M. fijiensis lesion expansion was assessed by applying fungicide to a $23 \times 23 \mathrm{~cm}$ area on the adaxial or abaxial surface of banana leaves (leaf 4) showing first-stage infection streaks (15). Lesions were measured immediately prior to the single chlorothalonil application. Lesions were measured again 1 and 2 weeks later by placing an acetate transparency film over a marked area on the leaf and marking the size of 10 lesions directly on the transparency. The same 10 lesions were measured throughout the study. Lesion expansion was compared between fungicide-treated leaves and controls. The experimental design was a randomized complete block with eight replicates (leaves). The experiment was conducted twice. Data were analyzed by analysis of variance.

\section{RESULTS}

Infection studies. One-hundred percent of banana leaves inoculated with M. fijiensis ascospores on the abaxial surface expressed symptoms of black Sigatoka within 30 days. Only $10 \%$ of leaves inoculated on the adaxial surface resulted in infection symptoms in the first experiment, and none of the leaves showed infection symptoms in the second experiment. Infection resulting from inoculations of the abaxial leaf surface appeared sooner when the emerging leaf was inoculated (18 days) than with the inoculation of leaves 1 and 2 (30 days). Additionally, the formation of necrotic tissue containing $M$. fijiensis pseudothecia was first noted at 36 days after inoculation in the emerging leaf compared with 55 days after inoculation of leaves 1 and 2 . Inoculation of the emerging leaf resulted in a distinct banding pattern of lesions concentrated at the leaf margin and corresponding to the abaxial leaf area, which was exposed at the time of inoculation.

Fungicide studies. Chlorothalonil application to the abaxial leaf surface resulted in significantly $(P<0.05)$ better disease control than chlorothalonil applied to the adaxial surface (Table 1). When the emerging leaf was unprotected, application of fungicide to the adaxial leaf surface (treatment 6) resulted in $0 \%$ control in the first experiment and $13 \%$ control in the second experiment compared with 76 and
$81 \%$ control for leaves receiving an application on the abaxial surface (treatment 5 ). This difference in disease control obtained with an abaxial versus adaxial leaf surface chlorothalonil application was visually obvious (Fig. 1). Leaves receiving fungicide on both leaf surfaces (treatment 7) had significantly $(P<0.05)$ better disease control than leaves treated only on the abaxial surface (treatment 5) when the leaf was not protected during its emergence.

Protecting the emerging leaf with either a polyethylene bag or with chlorothalonil improved disease control. A single application of chlorothalonil on the 4-day-old emerging leaf (Table 1, treatment 12) resulted in 81 to $84 \%$ control and an infection pattern that was limited to the area on the abaxial surface to the left of the midvein (Fig. 2). This area was unexposed at the time of fungicide application and did not receive visible fungicide deposit. An additional fungicide application to the abaxial surface at the leaf 1 stage (treatment 9) improved the level of control to between 99 and $100 \%$. When the emerging leaf was protected with a polyethylene bag but received no fungicide application in the leaf 1 stage (treatment 4 ), disease control was near $0 \%$, indicating that infection occurring at the leaf 1 stage and later is adequate to result in high disease severity.

All of the fungicides tested reduced pseudothecia production in infected leaf tissue, which ranged from 37 to $73 \%$ reduction compared with the untreated con-

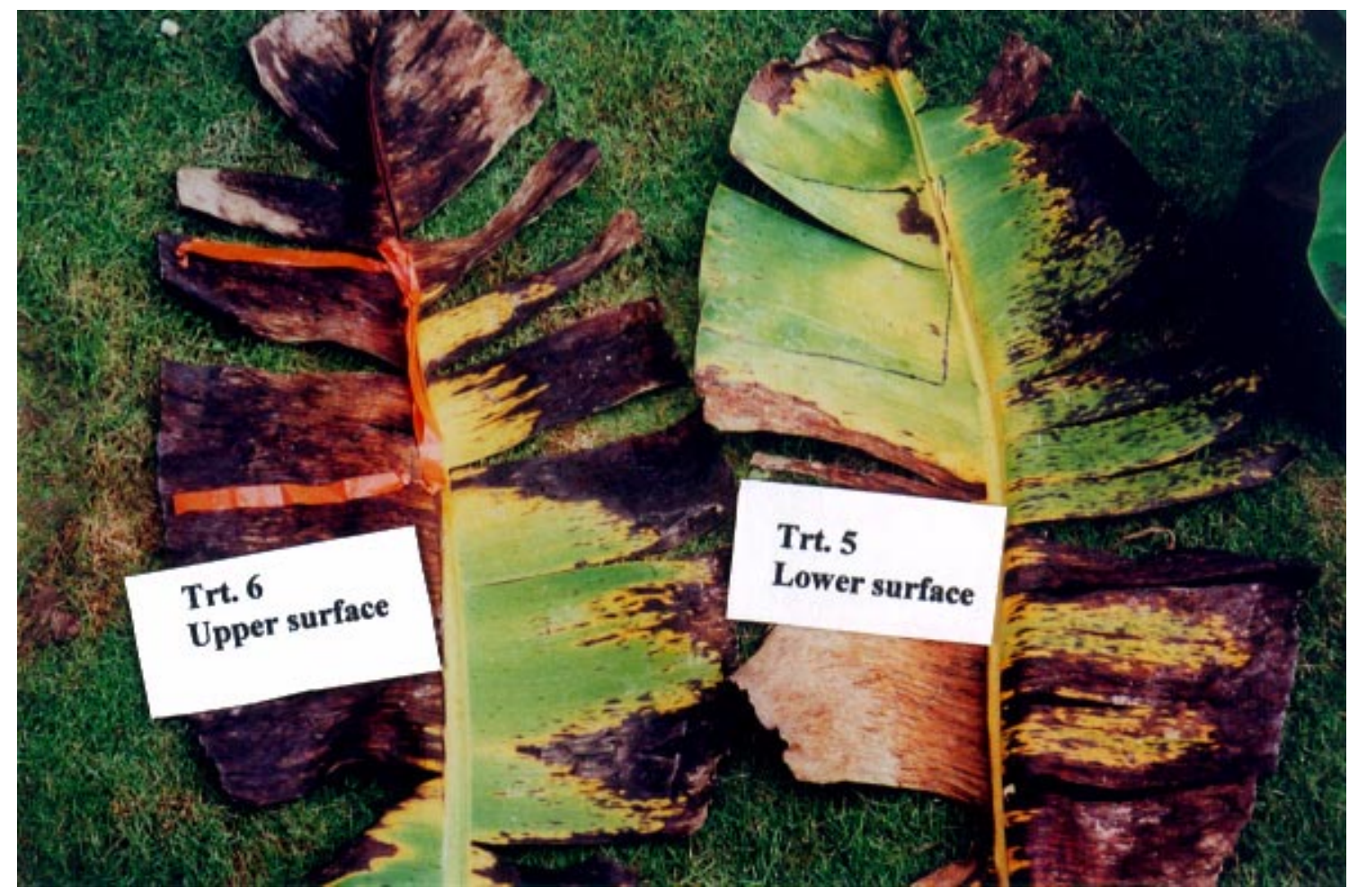

Fig. 1. Banana leaves with black Sigatoka symptoms. Left: Leaf sprayed with chlorothalonil on the adaxial surface in the area marked with orange ribbon. Right: Leaf sprayed with chlorothalonil on the abaxial surface in a $23 \times 23 \mathrm{~cm}$ area (marked by black lines). The leaf on the left corresponds to treatment 6 , and the leaf on the right corresponds to treatment 5 , Table 1. 
trol (Table 2). The highest reduction in pseudothecia numbers was obtained with propiconazole and azoxystrobin. Chlorothalonil and tridemorph were similar to each other in their levels of suppression of pseudothecia production. None of the fungicides affected the viability of ascospores discharged onto agar dishes from pseudothecia that developed in the sprayed leaves. Ascospore germination ranged from 97.1 to $99.8 \%$ with no significant differences among treatments and the unsprayed control.

Germ tube elongation bioassay. Chlorothalonil arrested germ tube growth of ascospores when applied $48 \mathrm{~h}$ after ascospore inoculation onto leaf disks (Fig. $3)$. In the untreated control, germ tube length increased over $100 \mu \mathrm{m}$ between 48 and $96 \mathrm{~h}$ after inoculation.

Effect of chlorothalonil on lesion expansion. Chlorothalonil applied to the abaxial leaf surface after the appearance of infection lesions reduced lesion expansion compared with the untreated control (Fig.
4). In contrast, application of chlorothalonil to the adaxial surface had no apparent effect on lesion expansion. Lesion area in this treatment increased from $2.5 \mathrm{~mm}^{2}$ to approximately $21 \mathrm{~mm}^{2}$ over 2 weeks compared with a lesion area of only $5.5 \mathrm{~mm}^{2}$ after 2 weeks in leaves treated with chlorothalonil on the abaxial surface.

\section{DISCUSSION}

This study demonstrated that the primary infection site for $M$. fijiensis is the abaxial leaf surface. Inoculation of the adaxial surface with ascospores resulted in infection symptoms in only $10 \%$ of the samples in one experiment and none in the second experiment; whereas all leaves inoculated on the abaxial surface showed infection symptoms within 30 days. Additionally, chlorothalonil application on the abaxial leaf surface resulted in 76 to $100 \%$ control of black Sigatoka in contrast to 0 to $13 \%$ disease control obtained with chlorothalonil application to the adaxial surface in leaves that were not protected

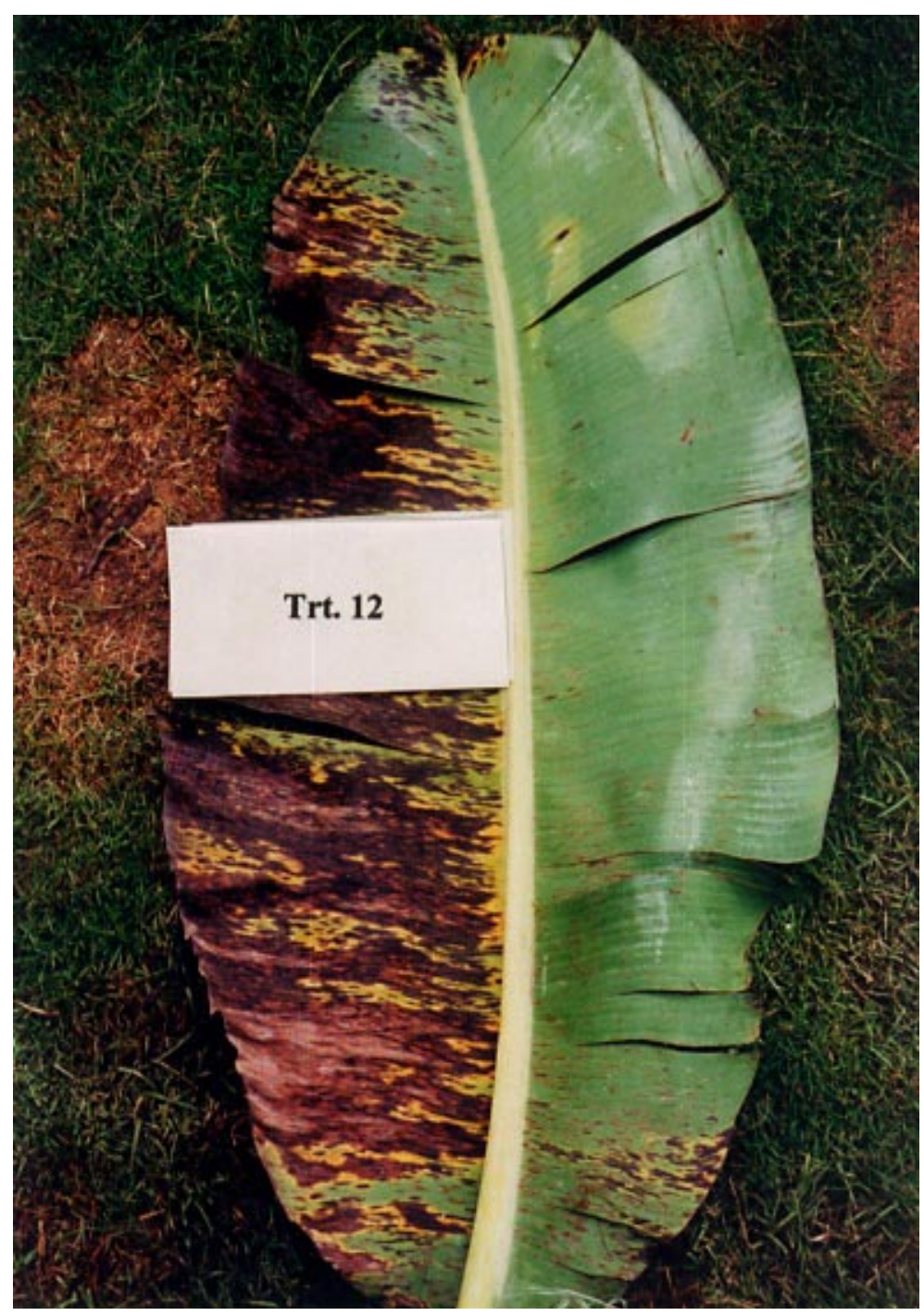

Fig. 2. Banana leaf with abaxial surface facing up showing disease control obtained with a single chlorothalonil application when the leaf was in the emerging stage. The area to the left of the midvein was not exposed to the spray at the time of application and shows high disease severity. The area to the right of the midvein has visible chlorothalonil residue and is relatively free of black Sigatoka symptoms. during their emergence (Table 1). Stover (14) stated that "the under surface of the leaf contains about four times as many stomata as the adaxial surface and infection is much more common on the former," but no data were provided. However, the findings in this study support Stover's conclusions. Possible explanations for the greater susceptibility of the abaxial leaf surface to $M$. fijiensis infection include differences in stomatal density, differences in phylloplane microclimate, and/or morphological differences such as the thickness and composition of the cuticle and epicuticular wax deposits (3). Differences in susceptibility between the adaxial and abaxial leaf surface are probably not due to effects on spore germination, since $M$. fijiensis ascospores germinate at equal frequencies on both leaf surfaces (19; J. R. Washington, unpublished). In the greenhouse, infection of $M$. fijiensis is routinely obtained by inoculating the adaxial leaf surface. However, symptom severity is greater when the abaxial leaf surface or both leaf surfaces are simultaneously inoculated (A. O'Leary, personal communication). It is likely that obtaining infection from adaxial leaf surface inoculation is easier in greenhouse-grown plants since these produce less epicuticular wax and show significant morphological differences $(3,10)$

The effect of leaf age on susceptibility to infection was not adequately addressed in this study. However, it was noted that the inoculation period in the emerging leaf was shorter than in fully expanded leaves. Freeman and Turner (3) reported that commencement of leaf wax deposition in banana occurred just prior to full expansion of the emerging leaf and that wax deposition became greater as leaf age increased. Additionally, they noted that stomata in older leaves often became occluded with wax, suggesting a possible effect on the susceptibility of leaves to infection by $M$. fijiensis. Stover $(14,16)$ reported that younger leaves are more susceptible to infection by $M$. fijiensis infection than older leaves, an observation also reported for yellow Sigatoka (7). Mobambo et al. (8) observed a slower development of black Sigatoka symptoms in plantain (Musa spp., AAB group) cultivars after

Table 2. Production of pseudothecia of $\mathrm{Myco-}$ sphaerella fijiensis in fungicide-treated banana leaves

\begin{tabular}{lcc}
\hline & \multicolumn{2}{c}{ Pseudothecia per $\mathbf{c m}^{\mathbf{2}}$} \\
\cline { 2 - 3 } Treatment & Experiment 1 & Experiment 2 \\
\hline Tridemorph & $8.1 \mathrm{~b}^{\mathrm{z}}$ & $3.4 \mathrm{~b}$ \\
Propiconazole & $4.5 \mathrm{c}$ & $1.9 \mathrm{c}$ \\
Azoxystrobin & $4.5 \mathrm{c}$ & $1.9 \mathrm{c}$ \\
Chlorothalonil & $10.4 \mathrm{~b}$ & $3.2 \mathrm{~b}$ \\
Control & $16.6 \mathrm{a}$ & $5.5 \mathrm{a}$ \\
\hline
\end{tabular}

${ }^{\mathrm{z}}$ Means followed by the same letter in each column are not significantly different $(P>$ 0.05 ) according to Tukey's test. 
flowering compared with before flowering, suggesting a change in host susceptibility with age.

The effects of fungicides on production of pseudothecia (Table 2) were very similar to those reported by Stover and Dickson (18). Propiconazole reduced pseudothecia production by $69 \%$ in this study and by $63 \%$ in Stover and Dickson's study; chlorothalonil reduced pseudothecia production by $40 \%$ in this study and by $28 \%$ in Stover and Dickson's study. The observation that chlorothalonil reduced pseudothecia production in both studies is surprising in view of the poor level of suppression of disease severity (percent area necrotic) that was obtained with chlorothalonil applied only on the adaxial surface. Similarly, the significant reduction in lesion expansion is not an effect typically associated with protectant fungicides like chlorothalonil. However, chlorothalonil's effect of arresting hyphal growth in the postgermination phase (Fig. 3) may be the mechanism by which the rate of lesion expansion is slowed. Stover (15) reported that $M$. fijiensis hyphae exit and enter stomata as they grow across the leaf surface and hypothesized that this was important for lesion expansion. In studies with Phytophthora infestans, Bruck et al. (1) reported that, in addition to suppressing sporangia germination, chlorothalonil and mancozeb reduced sporangia production and reduced lesion expansion.

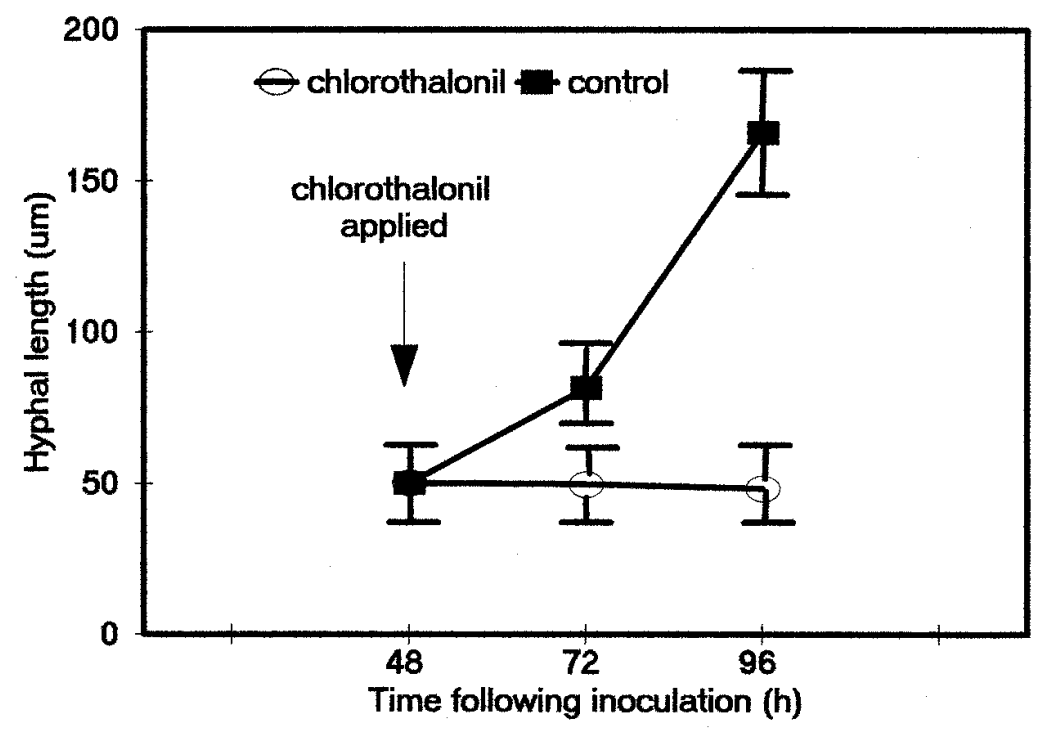

Fig. 3. Mean hyphal length of germinated ascospores of Mycosphaerella fijiensis at 48, 72, and $96 \mathrm{~h}$ after inoculation of ascospores onto banana leaf disks. In the chlorothalonil treatment, chlorothalonil (Bravo 720) was applied (1.05 kg a.i. ha $\left.{ }^{-1}\right) 48 \mathrm{~h}$ after inoculation of leaves with ascospores.

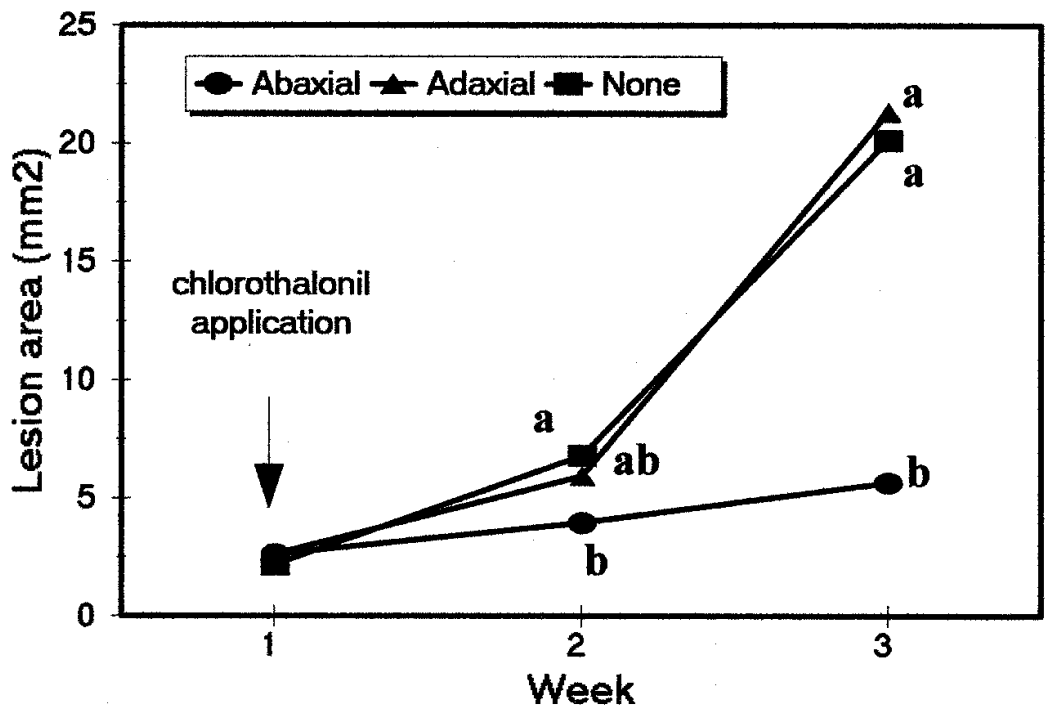

Fig. 4. Lesion size of Mycosphaerella fijiensis 0 to 2 weeks after a single chlorothalonil application $\left(1.08 \mathrm{~kg}\right.$ a.i. $\left.\mathrm{ha}^{-1}\right)$ applied to either the adaxial or abaxial leaf surface. Chlorothalonil was applied at week 1 . Points marked with the same letter are not significantly different $(P>0.05)$ according to Tukey's test.
The importance of depositing chlorothalonil on the abaxial leaf surface was clearly demonstrated by the results shown in Table 1 and Figure 4. These findings are very similar to the reported interactions between Bordeaux mixture and infection by $M$. musicola $(5,6)$ and are congruous with the results from the infection experiments in this study. The observation that the presence of chlorothalonil on the adaxial surface had an appreciable effect in some treatments can be explained by the occasional infection that occurs there and possibly by a reduction of secondary infection caused by hyphal growth across the leaf surface. The importance of protecting the emerging leaf was demonstrated by the disease-reducing effects of a chlorothalonil application or covering the leaf with a polyethylene bag during leaf emergence. Leaves that had no protection during their emergence showed a higher disease severity overall.

The findings of this study indicate the importance of applying protectant fungicides with sufficient frequency in order to increase the probability that the abaxial leaf surface will receive sufficient fungicide deposit during aerial applications. Washington et al. (22) showed that the small deposits of chlorothalonil on the abaxial leaf surface are redistributed in dew water. For this reason and because the $\mathrm{EC}_{50}$ value of chlorothalonil for $M$. fijiensis ascospores is low ( 0.01 to $0.03 \mathrm{ppm})$ (22), effective disease control may be achieved by this redistributed fungicide. However, development of spray technology or practices that increase fungicide deposit on the abaxial surface of banana leaves during an aerial application would likely improve disease control and may allow reduction of currently recommended fungicide rates or reduce the number of applications.

The conclusion by Stover (17) that protectant fungicides cannot control M. fijiensis ascospores impacting on the unfurling heartleaf was not supported by the findings in this study. A single application of chlorothalonil to a 4-day-old emerging leaf resulted in 99.4 to $100 \%$ disease control in the treated area. Additionally, a zone of disease control larger that the sprayed area could be observed (Fig. 1). This may be due to the presence of small concentrations of chlorothalonil present in dew water and redistributed over the leaf surface $(20,22)$. With the closely related pathogen $M$. musicola, hyphae were observed to grow over the leaf surface for 2 to 6 days or longer before forming appressoria and penetrating a stoma (4). This long period between inoculation and stomatal penetration would favor the ability of a protectant fungicide such as chlorothalonil to arrest infection on the abaxial leaf surface. Chlorothalonil's effect on retarding lesion expansion would also contribute to the control of the disease. 


\section{ACKNOWLEDGMENTS}

We thank D. Ingram, J. French, R. Moser, and M. Grove for their support of this research.

\section{LITERATURE CITED}

1. Bruck, R. I., Fry, W. E., Apple, A. E., and Mundt, C. C. 1981. Effect of protectant fungicides on the development stages of Phytophthora infestans in potato foliage. Phytopathology 71:164-166.

2. Calpouzos, L., Brun, W. A., Theis, T., and Colburg, C. 1960. A precision spray technique for evaluating oils for Sigatoka disease control on individual plant leaves in the field. Phytopathology 50:69-72.

3. Freeman, B., and Turner, W. 1985. The epicuticular waxes on the organs of different varieties of banana (Musa spp.) differ in form, chemistry, and concentration. Aust. J. Bot. 33:393-408.

4. Goos, R. D., and Tschrich, M. 1963. Greenhouse studies on the Cercospora leaf spot of banana. Trans. Br. Mycol. Soc. 46:321-330.

5. Klein, H. H. 1961. Effects of fungicides, oil, and fungicide-oil-water emulsions on development of Cercospora leaf spot of bananas in the field. Phytopathology 51:294-297.

6. Leach, R. 1946. Banana leaf spot (Mycosphaerella musicola) on Gros Michel variety in Jamaica. Government Printer, Kingston, Jamaica.

7. Meredith, D. S. 1970. Banana leaf spot disease (Sigatoka) caused by Mycosphaerella musicola Leach. No. 11. Commonw. Mycol. Inst., Kew, Surrey, Eng.

8. Mobambo, K. N., Gauhl, F., Pasberg-Gauhl, C., and Zuofa, K. 1996. Season and plant age affect evaluation of plantain for response to black Sigatoka disease. Crop Prot. 15:609614.

9. Romero, R. A., and Sutton, T. B. 1997. Sensitivity of Mycosphaerella fijiensis, causal agent of black Sigatoka of banana, to propiconazole. Phytopathology 87:96-100.

10. Sandoval, J. A., Muller, L. E., and Weberling, F. 1992. Foliar morphology and anatomy of Musa c. v. Grand Nain (AAA) plants grown in vitro during hardening compared to fieldgrown plants. Fruits 49:37-46.

11. Simmonds, J. H. 1939. Influence of seasonal conditions on the development of Cercospora leaf spot of the banana, with special reference to the control programme. Queensl. Agric. J. 52:633-647.

12. Stahel, G. 1937. Notes of Cercospora leaf spot of bananas (Cercospora musae). Trop. Agric. Trinidad 14:257-264.

13. Steel, R. G. D., and Torrie, J. H. 1980. Principles and Procedures of Statistics. 2nd ed. McGraw-Hill Book Co., New York.

14. Stover, R. H. 1972. Banana, Plantain, and Abaca Diseases. Commonw. Mycol. Inst., Kew, Surrey, Eng.

15. Stover, R. H. 1980. Sigatoka leaf spots of bananas and plantains. Plant Dis. 64:750-756.

16. Stover, R. H. 1986. Disease management strategies and the survival of the banana industry. Annu. Rev. Phytopathol. 24:83-91.

17. Stover, R. H. 1989. Sigatoka leaf spots: Thirty years of changing control strategies: 19591989. Proc. X Annu. Meet. ACORBAT, San Jose, Costa Rica.

18. Stover, R. H., and Dickson, J. D. 1985. Effect of systemic and protectant fungicides on perithecia production by Mycosphaerella fijiensis var. difformis in banana leaves. Memorias VII Reunion ACORBAT, San Jose, Costa Rica.

19. Vasquez, N., Tapia, A. C., and Galindo, J. J. 1989. Ultrastructural studies of the infection process of Mycosphaerella fijiensis on Musa cultivars. Pages 191-200 in: Proc. Annu. Meet. ACORBAT, San Jose, Costa Rica.

20. Washington, J. R. 1997. Relationship between the spray droplet density of two protectant fungicides and the germination of $\mathrm{Myco}$ sphaerella fijiensis ascospores on banana leaf surfaces. Pestic. Sci. 50:233-239.

21. Washington, J. R., and Cruz, J. 1996. Distribution of Mycosphaerella fijiensis ascospores and conidia on the leaf surface in relation to he location in the banana leaf canopy. (Abstr.) APS/MSA Joint Annual Meeting, July 27-31, Indianapolis, IN. p. 85.

22. Washington, J. R., Cruz, J., and Fajardo, M. 1998. Detection of chlorothalonil in dew water following aerial spray application and its role in the control of black Sigatoka in banana. Plant Dis. 82:1191-1198. 